\title{
LETRAMENTO E GAMES: PRÁTICAS MOTIVACIONAIS E AUTÔNOMAS
}

\section{LITERACY AND GAMES: MOTIVATIONAL PRACTICES AND AUTONOMY}

\author{
Larissa de Carvalho Cerqueira ${ }^{1}$, \\ Maria de Fátima Dórea ${ }^{1}$, \\ Jéssica Vieira ${ }^{1}$, \\ Marcelle Gomes de Jesus ${ }^{1}$, \\ Lynn Alves ${ }^{1,2}$ \\ (1) Universidade do Estado da Bahia (UNEB) \\ e-mails: larissac.cerqueiral6; mariadefatimadorealuciano; jessvsp; marcellegomes.contato@gmail.com
}

\author{
(2)SENAI CIMATEC-BA \\ e-mail:ynnalves@gmail.com
}

Letramento, Gamebook, Autonomia

O presente artigo pretende discutir as características do letramento presentes no universo do Gamebook - Guardiões da floresta e suas implicações na motivação e autonomia do jogador. Para isso, analisaremos os dados construídos em parceria com os sujeitos da pesquisa, crianças do $3^{\circ}$ e $4^{\circ}$ anos de uma Escola Municipal de Salvador, em interação com o Gamebook Guardiões da Floresta - GB. Esta mídia visa estimular as funções executivas das crianças. Os resultados da pesquisa indicam que este grupo de crianças ainda em processo de alfabetização tem dificuldade em atribuir significado aos diferentes elementos que compõem o universo do GB, isto é, indo além dos textos. Portanto, apresentando dificuldades para avançar nos desafios e concluir as missões. No entanto, a mediação dos outros pares mobiliza esses leitores-jogadores para adotar práticas de interação com mais autonomia.

\section{Literacy, Gamebook, Autonomy}

The present article intends to discuss the characteristics of literacy present in the universe of the Gamebook Guardians of the forest and its implications in the motivation and autonomy of the player. For this, we will analyze the data constructed in partnership with the research subjects, children of the $3^{\circ}$ and $4^{\circ}$ grades a Municipal School of Salvador, in interaction with the Gamebook - Guardians of the forest - GB. This media aims to stimulate the executive functions of children. The results of the research indicate that this group of children still in the process of literacy has difficulty in assigning meaning to the different elements that compose the GB universe, that is, going beyond the texts. Therefore, presenting difficulties to advance the challenges and complete the missions. However, the mediation of the other peers mobilizes these player-readers to adopt practices of interaction with more autonomy.

\section{Introdução}

A sociedade contemporânea vem sendo marcada pela presença intensa da mediação das tecnologias digitais que mudam a forma das pessoas se relacionarem, aprenderem, se mobilizar por causas políticas, sociais, entre outras. Além disso, o universo do ciberespaço possibilitou a emergência do E-commerce, no qual distintas negociações são 
$16^{\circ}$ Ergodesign - Congresso Internacional de Ergonomia e Usabilidade de Interfaces Humano Tecnológica: Produto, Informações Ambientes Construídos e Transporte

$16^{\circ}$ USIHC - Congresso Internacional de Ergonomia e Usabilidade de Interfaces Humano Computador

CINAHPA | 2017 - Congresso Internacional de Ambientes Hipermídia para Aprendizagem. realizadas. Assim, a habilidade de letramento digital se constitui condição sine qua non, sendo indicada inclusive como uma das exigências para o século XXI.

Neste contexto, os jogos digitais se configuram em espaços lúdicos, interativos e imersivos para o desenvolvimento de diferentes tipos de letramento, por sua diversidade de linguagens, isto é, imagética, textual, sonora, hipertextual, digital, artística, entre outras.

As pesquisas apontam o crescimento de jogos voltados para as distintas idades e gênero, se constituindo em espaços de aprendizagem que desafiam os seus jogadores a solucionar problemas, desenvolvendo funções executivas, como o planejamento, a exemplo de jogos como o Lumosity, Peak, Pedro no acampamento, entre outros. Deste modo, essas mídias podem promover parcerias no cenário escolar para uma

aprendizagem mais significativa, isto é, a atribuição de sentidos ao que vem sendo estudado na escola.

$\mathrm{O}$ universo escolar pode interagir com os games a partir de três perspectivas: a) com a mediação de jogos desenvolvidos especialmente para cenários educativos, a exemplo do Gamebook - Guardiões da Floresta que integra elementos dos games e dos appbooks; b) jogos comerciais que podem ser integrados à dinâmica da escola, a exemplo, do Minecraft; c) a utilização de ferramentas para desenvolvimento de jogos, a exemplo do Scratch [KLOPFER et al. 2009]. As possibilidades são inúmeras, passando desde a criação de jogos digitais apenas para esse fim até a apropriação de jogos comerciais que apresentam uma estética e jogabilidade diferenciadas que mobilizam e engajam os jogadores.

Neste contexto, a criação de estratégias para potencializar os distintos níveis de letramento dentro do universo escolar, por parte dos professores e alunos, torna-se um grande desafio, na medida em que encontramos ainda um abismo entre professores e alunos no que se refere à fluência digital. As crianças oriundas de classes sociais mais favorecidas têm acesso a uma diversidade de ambientes semióticos que possibilita a estimulação e desenvolvimento de multiletramentos. Em contraponto, os alunos da rede pública, embora já indiquem acesso aos dispositivos móveis e jogos digitais ainda apresentam dificuldades relativas à alfabetização. Embora os conceitos de alfabetização e letramento estejam relacionados, eles são compreendidos de forma distinta. O letramento é muito mais que saber sobre o funcionamento da língua escrita, mas envolve habilidades relacionadas com o uso tanto da leitura quanto da escrita na prática social [SOARES, 2004].

Logo ser letrado na perspectiva de Gee [2004], que sintoniza com a de Soares, é a forma como as pessoas utilizam as habilidades de ler e escrever, conectando-as às suas necessidades, valores e práticas que envolvem seu contexto social. Dentro desse cenário, iniciamos um processo investigativo e colaborativo na Escola Municipal Roberto Santos, com a mediação do Gamebook Guardiões da Floresta (GB) para que motivasse as crianças a atribuir sentidos ao universo da cultura letrada e digital, estimulando assim o desenvolvimento de novas formas de letramento, exercitando práticas autônomas.

\section{Gamebook e Serious Games}

Nos últimos anos, a indústria de jogos tem crescido e alcançado níveis tecnológicos cada vez mais sofisticados, em função da diversidade de técnicas que vem emergindo para produção destas mídias. No cenário brasileiro, os games têm seus destaques, não apenas para um público infantojuvenil, mas alcançando outras gerações que não nasceram, necessariamente, imersas nesse mundo digital. Apesar de o Brasil não ter uma indústria de jogos forte e expressiva no cenário mundial, é um dos países que mais consomem esses produtos [ASSOCIAÇÃO BRASILEIRA DAS DESENVOLVEDORAS DE JOGOS ELETRÔNICOS, 2004].

No Brasil tem surgido algumas iniciativas para agregar os desenvolvedores independentes, a exemplo da Bind (Bahia Indie Game Developers), um coletivo que tem como objetivo reunir os desenvolvedores e pessoas que sejam interessadas no setor de game do estado da Bahia. Além disso, surgiram novos cursos sobre essa área, principalmente voltado especificamente para jogos digitais, um exemplo é o novo curso de Graduação

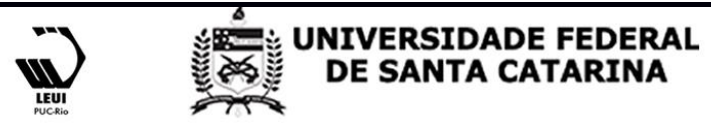




\section{$16^{\circ}$ \\ ERGODESIGN USIHC CINAHPA}

$16^{\circ}$ Ergodesign - Congresso Internacional de Ergonomia e Usabilidade de Interfaces Humano Tecnológica: Produto, Informações Ambientes Construídos e Transporte

$16^{\circ}$ USIHC - Congresso Internacional de Ergonomia e Usabilidade de Interfaces Humano Computador

CINAHPA | 2017 - Congresso Internacional de Ambientes Hipermídia para Aprendizagem.
Tecnológica em Jogos digitais, oferecido pela Universidade do Estado da Bahia (UNEB). Além disso, foram consolidados eventos de divulgação que apresentam games, pesquisas e propostas de inovações acerca desse tema. São exemplos desses eventos o Seminário Jogos Eletrônicos, Educação e Comunicação (SJEEC), que está em sua 12ª edição e o Simpósio Brasileiro de Jogos e Entretenimento Digital (SBGames) que realizará sua $16^{\mathrm{a}}$ edição. Um jogo apresenta características que tornam possível a imersão e engajamento dos jogadores nos games, tais como desafios, metas, feedback, premiação e, principalmente, práticas colaborativas e cooperativas. Os jogos digitais nos últimos anos têm sido objeto de investigação, especialmente com o foco das contribuições dessa mídia para aprendizagem [ALVES, RIOS e CALBO, 2013]. Segundo Morais et al [2011], os jogos computacionais que tem como finalidade o ensino de determinada disciplina, ou mesmo exercitar as habilidades ligadas ao comportamento, assim como suas capacidades operacionais, são conhecidos como serious games ${ }^{1}$. Este modelo de jogo une aspectos como diversão, modelos de avaliação e de planejamento.

Os serious games podem ser responsáveis pelo resgate do interesse do aluno, facilitam o aprendizado, favorecem a capacidade da retenção de informações, exercitam as funções mentais e intelectuais do jogador, são prazerosos, estimulam a criatividade e imaginação [CÂMARA, 2014]. Nesse contexto percebe-se o crescimento do desenvolvimento de jogos digitais voltados para a educação. Mapeamentos quantitativos de trabalhos brasileiros referentes a jogos digitais, como o de Fragoso et al. [2015], revelam a educação como área de conhecimento predominante em eventos da área de Comunicação (Intercom, Compós e ABCiber) entre os anos de 2000 e 2015, e representando 15\% dos 522 trabalhos analisados dos Programas de Pós-Graduação de 2012. Baseado nessa Análise de Conteúdo realizada por Fragoso, a coleta de trabalhos do SBGames e da

\footnotetext{
${ }^{1}$ As autoras corroboram com a ideia de que todos os jogos são sérios e podem se constituir como um ambiente favorável à estimulação cognitiva. Portanto, não é necessário criar uma categoria para se referir a jogos com esses objetivos.
}

Biblioteca Brasileira de Teses e Dissertações que possuíam os termos "jogo", "game" e "videogame" (tanto no plural quanto no singular) no título, palavras-chave ou resumo demonstram a constante presença do tópico Educação [Fragoso et al., 2016]. Das Teses e Dissertações pesquisadas (de 1997 a 2015), esse tópico atingia $29 \%$ delas, enquanto que no SBGames (de 2006 a 2015) atingia $28,4 \%$, sendo neste último um tema presente em todas as Trilhas (estruturação que contempla a multidisciplinariedade dos jogos) do Simpósio, salvo a de Indústria. No total foram 1357 trabalhos analisados em que revelou-se o crescente interesse na pesquisa sobre games e educação no Brasil. O GB se insere nesse segmento.

\subsection{Sujeitos e Ambientes de pesquisa}

A pesquisa aqui descrita foi realizada no período de maio a dezembro de 2016, com 57 crianças do terceiro e quarto ano do turno matutino, do ensino fundamental I da Escola Municipal Governador Roberto Santos. A escolha dessa instituição foi efetivada principalmente por conta da abertura e interesse da escola em receber o grupo de pesquisa. Esse projeto foi aprovado pelo Comitê de Ética e apresentado e discutido com os professores e corpo técnico-administrativo da escola, a fim de realizar as adequações necessárias sintonizadas com as demandas e necessidades da instituição. Após a autorização da direção e professores, as pesquisadoras participaram da reunião com os pais e responsáveis a fim de apresentar o projeto e verificar a possibilidade de participação dos alunos, culminando com a assinatura dos Termos de Consentimento Livre Esclarecido (TCLE). Posteriormente, as crianças foram informadas sobre a investigação e sua dinâmica e todos que tiveram interesse em participar assinaram o Termo de Assentimento (TAC).

A dinâmica da pesquisa consistiu em três encontros semanais com os alunos, alcançando até doze interações por turma. O tempo médio de interação com o gamebook para um jogador modelo é de duas horas. Jogador modelo aqui compreendido como uma criança na faixa etária de 8 a 12 anos, alfabetizada e familiarizada com a 


\section{$16^{\circ}$ \\ ERGODESIGN USIHC CINAHPA}

$16^{\circ}$ Ergodesign - Congresso Internacional de Ergonomia e Usabilidade de Interfaces Humano Tecnológica: Produto, Informações Ambientes Construídos e Transporte

$16^{\circ}$ USIHC - Congresso Internacional de Ergonomia e Usabilidade de Interfaces Humano Computador

CINAHPA | 2017 - Congresso Internacional de Ambientes Hipermídia para Aprendizagem. mecânica dos jogos digitais e dispositivos móveis, já que o GB deve ser executado em tablets. Os encontros ocorriam em salas disponibilizadas pela direção da instituição, sendo a maioria das vezes na sala de informática. A partir de uma ficha elaborada para cada participante, com o objetivo de registrar os principais comportamentos observados durante a interação das crianças com o gamebook, percebemos que: $67,8 \%$ sabiam ler e compreender a narrativa do game, atuando de forma autônoma na interação com o ambiente; $10,7 \%$ não sabiam ler, necessitando da ajuda das pesquisadoras e dos colegas constantemente; e 21,4\% liam com dificuldade, não compreendendo, às vezes, a o que deveriam fazer. Essa constatação leva à reflexão, que será aprofundada ao longo deste trabalho, sobre o quanto o letramento e a compreensão do que é passado influenciam na forma como a criança interage e se motiva com o game.

\subsection{Gamebook Guardiões Da Floresta}

A mídia híbrida GB é um aplicativo com narrativa interativa, financiado pela CAPES, FAPESB, CNPq e UNEB, desenvolvido por uma equipe com expertises diferenciadas, com o objetivo de estimular as funções executivas (FE). As FE são habilidades cognitivas, que possibilitam ao sujeito realizar comportamentos orientados a objetivos e direcionados a metas, ajudando nas ações voluntárias, independentes, auto-organizadas [DIAS, MENEZES e SEABRA, 2010]. Essas operações compõem um conjunto de processos cognitivos e metacognitivos fundamentais ao controle e à regulação do comportamento, emoção e cognição [DIAS, 2013]. Exemplos dessas funções são: a iniciação e o planejamento de uma atividade; a sustentação da atenção; a flexibilidade; a inibição e o autocontrole; a monitorização; entre outras. [FONSECA, 2014].

A narrativa presente no ambiente proporciona uma experiência interativa no universo do folclore brasileiro e da Floresta Amazônica, na qual o sujeito assume o papel de leitor-jogador, imergindo na história de Lyu que está à procura, juntamente com seus pais, da Flor da Lua. Ao ter se perdido dos pais, que foram levados por homens da Fábrica Aragon - fábrica que explora clandestinamente os recursos da floresta- a personagem conta com a ajuda dos guardiões da floresta. Os guardiões são responsáveis por proteger a fauna e flora, lutando contra o desmatamento provocado por essa fábrica. Para que possa reencontrar seus pais e ajudar a conservar e proteger a floresta, Lyu precisará treinar suas habilidades, realizando todas as tarefas necessárias para alcançar o objetivo almejado. Em função do propósito de estimular as funções cognitivas, o GB foi estruturado levando em consideração a prática de habilidades relacionadas a essas funções. Dessa forma, os estímulos visuais (como a arte do jogo), o sistema de jogabilidade de exploração (o gameplay) e os minigames (MG) estimulam o jogador quanto às $\mathrm{FE}$, sempre em conformidade com o que a narrativa do jogo propõe.

Já sobre os aspectos relacionados à leitura (verbal ou não verbal) do game, a primeira característica é a narrativa semelhante à de histórias em quadrinhos (Figura 1). Nessa parte, há tanto imagens, como textos na parte inferior da tela, e, ainda, um narrador que também acompanha o texto e as imagens.

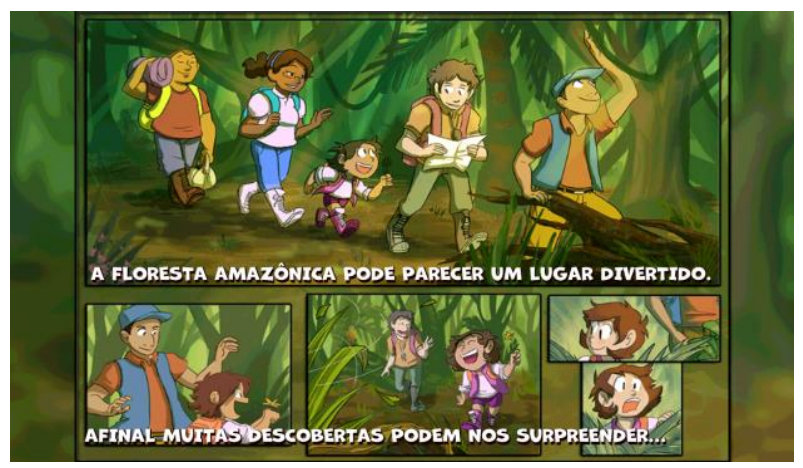

Figura 1: Parte da narrativa do capítulo 1 do GB.

Diálogos entre a personagem principal e os secundários (guardiões) também requerem a habilidade de leitura e compreensão (Figura 2). Uma agenda azul, o inventário, localizada na parte inferior - traz informações sobre vários pontos do GB (Pais de Lyu, flor da Lua, Amazônia entre outros), apresentado textualmente e no qual a criança pode acessá-lo a qualquer momento para obter informações. Outro ponto importante são os manuais e missões que aparecem e que explicam os próximos passos dentro do jogo (Figura 4 e 5). Caso não compreendam essas informações, a
Realização:

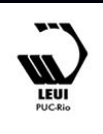




\section{$16^{\circ}$ \\ ERGODESIGN USIHC CINAHPA}

$16^{\circ}$ Ergodesign - Congresso Internacional de Ergonomia e Usabilidade de Interfaces Humano Tecnológica: Produto, Informações Ambientes Construídos e Transporte

$16^{\circ}$ USIHC - Congresso Internacional de Ergonomia e Usabilidade de Interfaces Humano Computador

CINAHPA | 2017 - Congresso Internacional de Ambientes Hipermídia para Aprendizagem. criança fica sem saber como prosseguir, necessitando da mediação de seus pares e/ou dos pesquisadores.

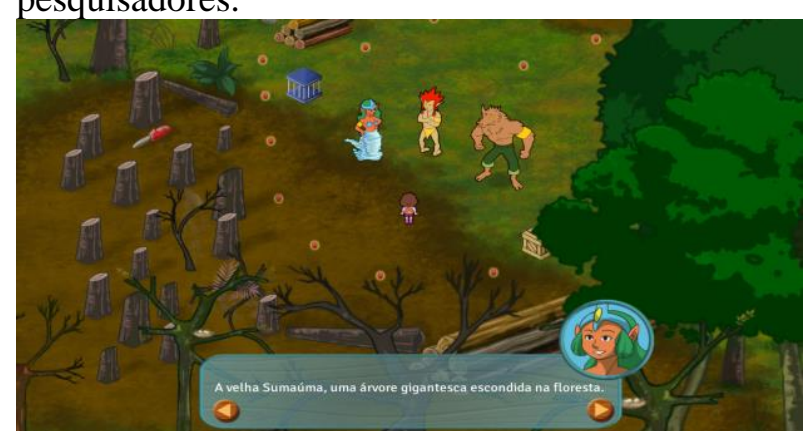

Figura 2: Diálogos na parte inferior da tela. Para avançar basta, clicar na seta a direta ou retornar em caso de dúvidas, através da seta esquerda.

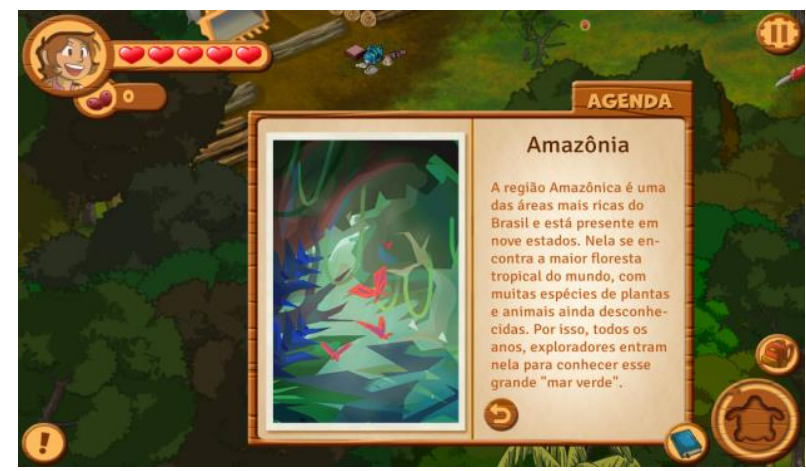

Figura 3: Agenda aberta na seção sobre a Amazônia.

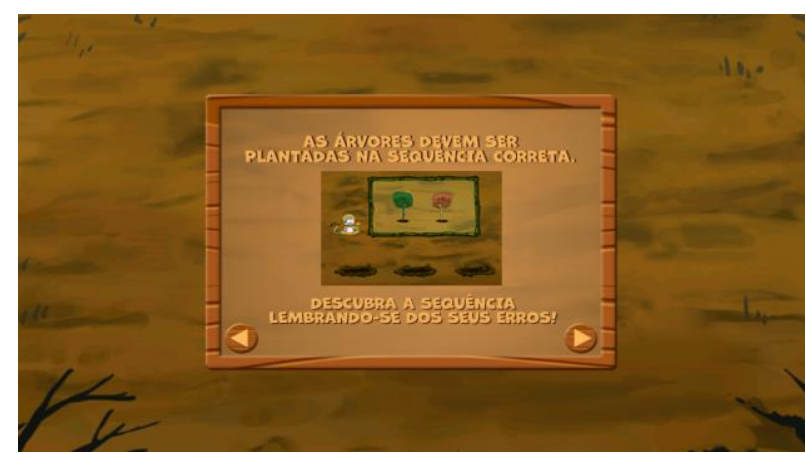

Figura 4: Manual para o do Minigame. A forma de interação é semelhante a presente nas cutscenes e gameplay.

Através desses diálogos e narrativas de Lyu com os guardiões, a criança é levada a refletir questões reais, como o desmatamento de florestas. Isso se relaciona com a forma que Murray [2003] considera os games: como histórias que se assemelham ao universo da experiência do dia a dia. Dessa forma, o GB pode se constituir em um campo rico de representações, simulando a relação com o real. Percebemos isso claramente, quando as crianças projetam conteúdos relacionados com suas vidas, incluindo até aspectos religiosos. Neste caso, tivemos o exemplo em que, uma menina de 10 anos, durante seu período de interação, se recusou a olhar para a imagem da personagem Iara. A garota escondia a figura do avatar utilizando as mãos, justificando tal ação a dizer que a Iara tinha um chifre e que não gostava disso. A imagem dos chifres, idealizado pela menina, na verdade era a coroa da personagem.

Além das narrativas, diálogos e instruções do jogo, a criança tem o desafio de relacionar os ícones e símbolos, como a mochila e as frutas, com a história de Lyu. Dessa maneira, exige-se do sujeito uma fluência em multiletramentos, que será melhor explorado na seção 3.1. Essa forma de leitura acontece devido ao surgimento dos novos espaços digitais (os ciberespaços), realidade dos chamados leitores imersivos [SANTAELLA, 2004].

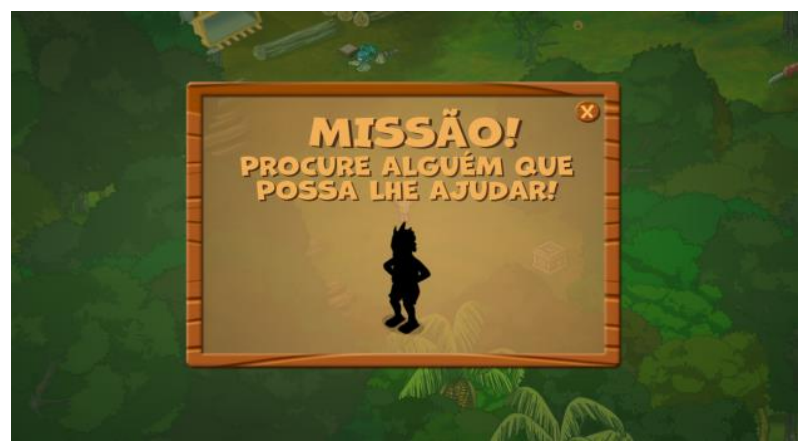

Figura 5: Exemplo de manual de missão que une aspectos verbais e não verbais, aliando diferentes símbolos.

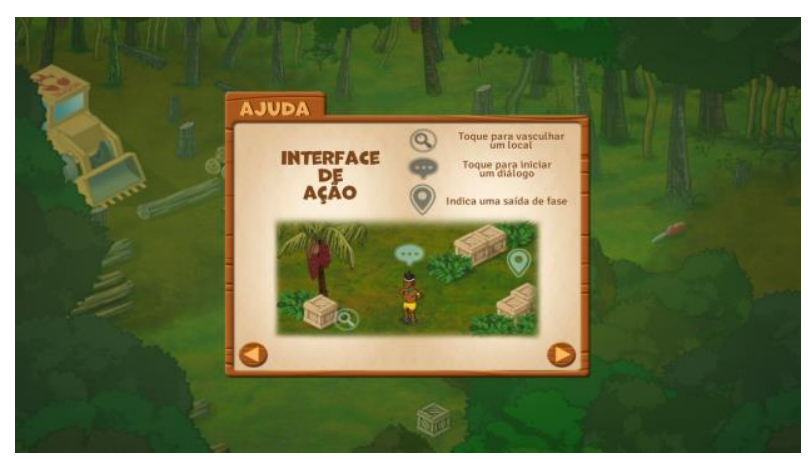

Figura 6: Símbolos importantes no progresso do jogo que precisam ser associados à sua funcionalidade.

\section{Realização:
WIV SANTA CATARINA




\section{$16^{\circ}$ \\ ERGODESIGN USIHC CINAHPA}

$16^{\circ}$ Ergodesign - Congresso Internacional de Ergonomia e Usabilidade de Interfaces Humano Tecnológica: Produto, Informações Ambientes Construídos e Transporte

$16^{\circ}$ USIHC - Congresso Internacional de Ergonomia e Usabilidade de Interfaces Humano Computador

CINAHPA | 2017 - Congresso Internacional de Ambientes Hipermídia para Aprendizagem.
Assim, o GB pode se constituir em um potencial campo de aprendizagem, proporcionando ao leitorjogador uma imersão prazerosa e atuante no universo simbólico do game.

\section{Games e letramento: influências na interação com o jogo}

A escola pública ou privada é uma instituição destinada à formação crítica dos seus alunos, criando um espaço coletivo e colaborativo para diferentes aprendizagens. O primeiro passo para a construção do conhecimento provocado pela escola é possibilitar a interação com a informação através dos vários veículos disponíveis na atualidade, sendo assim a primeira preocupação é com processo de alfabetização [SOARES, 2003]. Para Soares [2003], existe uma diferença, ainda que poucos educadores a percebam, entre o processo de alfabetização e letramento. A alfabetização é a capacidade de ler e escrever, entendida como a aquisição do sistema convencional de escrita [SOARES, 2004]; e o letramento vai além das capacidades citadas anteriormente, pois nesse segundo processo faz-se necessário o ensino em um contexto, onde a escrita e leitura ganhem sentido e significado para o aluno, ou seja, que possam ser aplicados em seu cotidiano [SOARES, 2003].

De acordo com Silva [2017], o letramento e a alfabetização devem ocorrer de forma simultânea, pois ao compreender que o sujeito está imerso num contexto de manifestações linguísticas pluri e multiculturais, o aprender a ler envolve muito mais que conhecer as letras e os fonemas, que aconteceria no início da alfabetização.

A fusão inadequada desses dois processos citados pode gerar diversos transtornos para esses alunos, pois, quando os educadores percebem que os mesmos reconhecem a estrutura das palavras, acabam não se atentando para a compreensão desses alunos sobre o conteúdo lido.

Consequentemente, os alunos avançam sem uma boa capacidade de interpretação textual, dificultando a inserção desses indivíduos no ambiente social, principalmente, no mercado de trabalho [SOARES, 2003]. Soares [2004] afirma que ambos os processos devem ser reconhecidos como indissociáveis e interdependentes, pois a alfabetização só adquire sentido quando é desenvolvida em conjunto com a prática social da leitura e escrita, logo, o estabelecimento do letramento.

Para uma significativa aprendizagem, faz-se necessário que os profissionais da educação reconheçam a importância do conhecimento prévio, ou seja, as informações que foram fornecidas aos indivíduos durante o seu desenvolvimento, e que servirão de base para o conhecimento a ser construído [SOARES, 2003].

\subsection{Multiletramento: outra perspectiva}

Existem diversas dimensões que interagem com o desenvolvimento do fenômeno de letramento, tais como o som, imagens e não apenas a dimensão linguística, demonstrando um aspecto denominado multiletramento. Nesse fenômeno, as diferentes facetas e a interação entre diversos fatores funcionam de forma colaborativa para a construção do processo de letramento, e, atualmente, há ainda a presença dos aparatos tecnológicos que fazem parte desta constituição [ROJO, 2012].

Esses recursos que a tecnologia está criando para a comunicação humana, como redes sociais e games, exige um olhar delicado para a forma como as crianças aprendem na escola, uma vez que há uma grande multiplicidade de aspectos tanto da linguagem, quanto da semiologia. Por isso as práticas precisam ser repensadas, com o intuito de englobar esse contexto sócio-histórico.

Silva [2017] corrobora esse pensamento e destaca a importância de pensar esse letramento de forma múltipla, pois a incorporação das tecnologias digitais no cotidiano dos sujeitos exige outras formas de aprendizagem da leitura e da escrita, ou seja, outras práticas de letramento, que permitam outros modos de pensar, agir, estar e interagir com o mundo, o que não exclui a leitura do impresso, apenas soma com as novas possibilidades. Ainda direcionando o olhar sobre a escola, Rojo [2012] enfatiza a necessidade de se pensar, e colocar em prática, uma Pedagogia dos Multiletramentos, que englobe os aspectos citados acima. Para que esse objetivo seja alcançado é necessário levar em consideração as preferências dos alunos [ROJO, 2012]. Talvez esse seja o

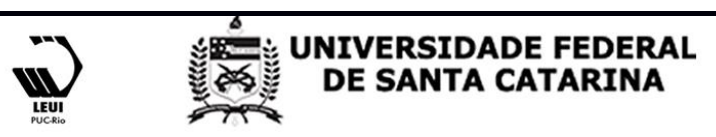


 CINAHPA}

$16^{\circ}$ Ergodesign - Congresso Internacional de Ergonomia e Usabilidade de Interfaces Humano Tecnológica: Produto, Informações Ambientes Construídos e Transporte

$16^{\circ}$ USIHC - Congresso Internacional de Ergonomia e Usabilidade de Interfaces Humano Computador

CINAHPA | 2017 - Congresso Internacional de Ambientes Hipermídia para Aprendizagem. principal desafio da realidade das escolas brasileiras: buscar uma maneira de engajar os alunos que frequentam essas redes de ensino, considerando as salas lotadas e com poucas condições físicas.

Levando em consideração a imersão da maior parte da população com os aspectos tecnológicos e a disponibilidade de uma série de equipamentos eletrônicos cedidas pelo governo em algumas escolas, os jogos digitais podem constituir-se uma importante ferramenta de aprendizagem, uma vez que:

Os jogos trazem em si uma infinidade de conceitos que estimulam a aprendizagem, pois permitem a interação com o meio e a construção coletiva de conceitos e experiências, bem como a geração de conhecimento [SENA et al., 2016, p. 2].

É importante ressaltar que a alfabetização, o letramento e o multiletramento não devem ser considerados como processos diferentes e excludentes, mas pelo contrário, esses processos são concebidos como interdependentes [SILVA, 2017]. Desta maneira, esses conceitos precisam ser pensados como etapas progressivas para um bom desempenho de um sujeito para a leitura adequada de palavras, signos e contextos.

Alves [2010] enfatiza sua crença que os sujeitos letrados precisam compreender, interpretar e interagir de forma contextualizada, nos distintos âmbitos semióticos. Isso inclui os games, pois de acordo com a autora, para emergir nesse ambiente os jogadores precisam desenvolver habilidades que visam à construção de sentidos e significados para esse universo midiático, para assim, atingir os objetivos propostos pelo jogo; entendendo que os sentidos e significados vão além das leituras dos textos, dos hipertextos, das histórias em quadrinhos presentes nas telas dos games.

Ao se pensar nesses fatores, através das interações realizadas com o GB no espaço da escola foi ratificada a hipótese de que é preciso desenvolver atividades que envolvam a estimulação dos indivíduos em uma leitura mais imersiva, pois cerca de $32,1 \%$ das crianças, que participaram dessas sessões, não sabiam ler ou possuíam dificuldades de entender e dar sentido à narrativa que foi disponibilizada às mesmas.
Aliado à questão da dificuldade no letramento, observou-se também o desinteresse pela leitura. Um exemplo é a relação que as crianças teceram com os textos do GB, tanto do que era necessário para o progresso do jogo, quanto das informações adicionais dos hipertextos, a exemplo da agenda (vide imagem 3), que não eram acessados com frequência pelos leitores-jogadores. O que também foi percebido na análise de interações com outro jogo, o Búzios [ALVES, RIOS e CALBO, 2013], no qual as crianças também evitavam os manuais explicativos e os hipertextos.

Outras experiências trazem situações semelhantes, como no caso da pesquisa descrita por Alves [2010] com o Tríade, game em 3D sobre a Revolução Francesa. Nesse relato, as imagens com predominância textual provocava nos jogadores um pequeno desprazer, já que exigiam um tipo de leitura convencional, semelhante aos que estão presentes nas atividades escolares comuns. As HQs que possuem uma maior quantidade de texto provocava a busca pela tecla de saída na tentativa de burlar a necessidade da leitura e voltar para a aventura de jogar.

A partir de outra pesquisa empírica realizada com dois jogos, De Paula [2011] destaca que além da necessidade da interpretação do texto, é preciso ser capaz de ler e extrair as informações necessárias para que o jogador possa compreender e se expressar a partir de um game, levando em consideração os desafios, as características e exigências desse artefato cultural. $\mathrm{O}$ autor concluiu que:

$$
\begin{aligned}
& \text { Foi visto que os jogadores ou ainda } \\
& \text { não são capazes de compreender } \\
& \text { muito bem as mensagens transmitidas } \\
& \text { pelos jogos, ou não estão interessados } \\
& \text { naquilo que eles transmitem (ou } \\
& \text { ambos) [DE PAULA, 2011, p. 124]. }
\end{aligned}
$$

Já Alves [2010] afirma que as dificuldades para a leitura podem estar relacionadas a dois tipos de letramentos:

$$
\begin{aligned}
& {[\ldots] \text { um relacionado com a leitura dos }} \\
& \text { textos e seu contexto, já que tinha } \\
& \text { relação com a compreensão dos } \\
& \text { objetivos do jogo; e outro relacionado } \\
& \text { com a jogabilidade, isto é, o } \\
& \text { letramento do âmbito semiótico do } \\
& \text { jogo, a expertise dos jogadores para se }
\end{aligned}
$$

Realização:

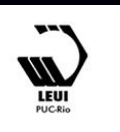




\section{$16^{\circ}$ \\ ERGODESIGN USIHC CINAHPA}

$16^{\circ}$ Ergodesign - Congresso Internacional de Ergonomia e Usabilidade de Interfaces Humano Tecnológica: Produto, Informações Ambientes Construídos e Transporte

$16^{\circ}$ USIHC - Congresso Internacional de Ergonomia e Usabilidade de Interfaces Humano Computador

CINAHPA | 2017 - Congresso Internacional de Ambientes Hipermídia para Aprendizagem. movimentar no universo do Tríade [p. 83].

A não compreensão resultava na falta de progressão no GB, provocando inquietação e frustração nos participantes, o que levou à mediação das responsáveis pela pesquisa. Isto ocorreu porque as crianças tinham interesse de conhecer a mecânica do jogo, e de acompanhar os colegas, fatores aliados à curiosidade e competição que o ambiente lúdico proporciona.

Dentro dessa perspectiva percebe-se que ambientes como o GB podem atuar no desenvolvimento de práticas de multiletramento, motivando o interesse de aprender não apenas a ler, mas entender o sentido.

Perante os desafios que implicam a formação de indivíduos letrados e da importância do multiletramento na sociedade contemporânea, que é dominada por uma cultura da escrita e pelas tecnologias da informação é que se propõe pensar sobre as implicações que essas competências trazem para a construção da autonomia do aluno [SOARES, 2015], bem como para a interação com diferentes ambientes multimodais, como o GB.

\section{Autonomia, letramento e games}

Segundo Deci \& Ryan [1987], autonomia é compreendida como uma autodeterminação para certo comportamento. Isso implica escolhas sobre o que fazer, o que não fazer, como fazer e quando findar a ação, traçando objetivos e planos.

Além disso, a autonomia é uma necessidade psicológica, configurando-se como um precursor motivacional capaz de prover energia proativa para uma determinada atividade [Reeve, 2011]. Consequentemente, tem-se uma promoção de aprendizado significativo e de desenvolvimento psicológico e social, decorrentes dessa atividade realizada.

Nesse processo, portanto, há uma interação constante de influência entre ambiente-indivíduo, promovendo autonomia, ocasionando motivação. E essa motivação leva à produção humana e a alterações no ambiente. Além disso, o ambiente ainda apresenta demandas que o indivíduo precisa responder e adaptar-se a [Reeve, 2011]. A partir desse conceito de autonomia, pode-se analisá-la dentro do universo dos games.
Considerando a definição de jogos por Araújo, Stein e Romão [2012], no sistema lúdico o jogador seria aquele quem toma as decisões, engajando na atividade de um desafio artificial. Isso significa que os games, de forma geral, proporcionam essa habilidade de autonomia.

Esse ambiente é representado pela mídia GB que propõe para as crianças desafios, feedbacks, oportunidades de escolha e atividades interessantes ao longo de sua estrutura narrativa bem como regras do que pode ou não fazer.

Consequentemente pode-se falar de uma influência direta dentro do jogo que produz novas formas de motivação para aquele que o joga. E, portanto, proporciona aprendizado e desenvolvimento para as crianças.

Referente à relação pesquisador-sujeito de pesquisa, pode-se falar em um ambiente apoiador, segundo a classificação de Deci e Ryan [1987]. Os ambientes encorajadores estimulam as escolhas enquanto os controladores pressionam em uma determinada direção. Nesse sentido, a partir da caracterização acerca desses ambientes apoiadores, a escuta atenciosa, o incentivo ao esforço independente das crianças, a priorização sobre as estratégias que as crianças queriam desenvolver foram proporcionadas pelas pesquisadoras, contribuindo para a autonomia das crianças. Essa conclusão foi consequência de uma avaliação cuidadosa das performances realizadas pelos sujeitos da investigação.

O letramento, como forma de interpretação de símbolos e conexão de informações, influencia diretamente na autonomia das crianças. De um lado, como não conseguiam ler ou entender as partes do jogo, como já foi dito, pediam muito ajuda das pesquisadoras, não imergindo no game por si mesmas. Por outro lado, o fato de escolher pedir ajuda, implica um nível de autonomia no sentido de, partindo da dificuldade de sentir-se letrado e compreendendo que as pesquisadoras leriam as informações para elas, as crianças traçaram um plano para continuar no jogo.

\section{Considerações Finais}

Portanto, depois de analisar os dados da pesquisa exposta, pode-se perceber que os jogos digitais podem ser um importante espaço de ensino-

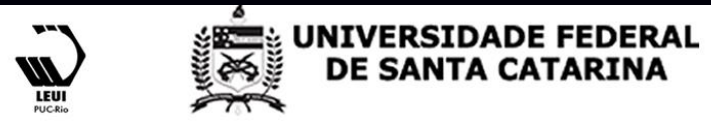




\section{$16^{\circ}$ \\ ERGODESIGN USIHC CINAHPA}

$16^{\circ}$ Ergodesign - Congresso Internacional de Ergonomia e Usabilidade de Interfaces Humano Tecnológica: Produto, Informações Ambientes Construídos e Transporte

$16^{\circ}$ USIHC - Congresso Internacional de Ergonomia e Usabilidade de Interfaces Humano Computador

CINAHPA | 2017 - Congresso Internacional de Ambientes Hipermídia para Aprendizagem. aprendizagem, principalmente no âmbito escolar, mesmo que, aos olhos de uma parcela da população, os mesmos sejam apenas para diversão. $O$ letramento foi um importante fator para $o$ desenvolvimento dos participantes com o GB, fazendo com que os letrados tivessem maior êxito e conseguissem finalizar o jogo com mais rapidez, pois entendiam as instruções que eram passadas através dos personagens da mídia.

Ainda que o nível de letramento tenha interferido na evolução do jogo dos alunos, não se pode afirmar que o mesmo também tenha agido sobre o grau de motivação dos participantes. Isto é afirmado, pois mesmo não entendendo a narrativa, muitas crianças pediam o auxílio das pesquisadoras com a finalidade de que elas pudessem informar qual o próximo passo a ser dado no game.

Com relação à autonomia, não poderíamos dizer a mesma coisa. Foi possível perceber que, pela falta de compreensão, os participantes, além de solicitar ajuda as pesquisadoras, também demonstravam medo para arriscar-se sem a resposta positiva das mediadoras.

Com isso, pode-se concluir que, além de toda a parte de lazer, proposta pelo game, este pode ser uma boa opção para estimular o letramento, visto que, o mal-entendimento deixa o aluno ainda mais curioso para saber o que está acontecendo no game, e o que pode acontecer. Além de estimular, os games podem ser pensados como uma estratégia para ajudar os professores a perceber quais os alunos necessitam de mais auxílio nas atividades relacionadas à leitura.

\section{BIBLIOGRAFIA}

\section{ASSOCIAÇÃO BRASILEIRA DAS DESENVOLVEDORAS DE JOGOS}

ELETRÔNICOS. Plano diretor da promoção da Indústria de Desenvolvimento de Jogos Eletrônicos no Brasil. Dezembro, 2004. DisponIvel na URL: www.abragames.org. Acesso em: 08 mar 2017. ALVES, L.; RIOS, V.; CALBO, T. Games: delineando novos percursos de interação. INTERSEMIOSE - Revista Digital, n. 04, p. 268-293, 2013.

ALVES, L. Letramento e games: uma teia de possibilidades. Educação \& Tecnologia, CEFE-
MG, Belo Horizonte, v. 15, n. 02, p. 76-86, 2010.

ARAUJO, M. H.; STEIN, M. S.; ROMÃO, J. J. S.

Jogo e serious games: conceito e bons princípios para análise do jogo SpaceCross, da

Volkswagen. SBGames, 9. Brasília, nov, 2012.

Disponível em:

<http://base.gamux.com.br/events/2012.11.02-

SBGames12/proceedings/papers/artedesign/AD_S hort1.pdf>. Acesso em 10 mar 2017.

CÂMARA, B. B. A. Motivação e games: o uso do jogo Angry Birds com estudantes para o ensino de física, 2014. $97 \mathrm{f}$. Dissertação (mestrado) - Universidade Federal de Pernambuco. CFCH. Pós-Graduação em Psicologia Cognitiva.

Disponível em:

<http://repositorio.ufpe.br/handle/123456789/1397

1> Acesso em: 30 nov 2016.

DECI, E. L. e RYAN R. M. The support of autonomy and the control of behavior. Journal of Personality and Social Psychology, 53, p. 10241037, 1987.

MORAIS, A. M., MACHADO, L. S.,VALENÇA, A. M. G. Planejamento de um Serious Game Voltado para Saúde Bucal em Bebês, Revista de Informática Teórica e Aplicada: vol 18, p. 158 175, 2011.

DE PAULA, G. N. A prática de jogar videogame como um novo letramento 2011. 125f.

Dissertação de mestrado - Instituto de Estudos da Linguagem. Universidade Estadual de Campinas, Campinas, 2011.

DIAS, N. M. Desenvolvimento e avaliação de um programa interventivo para promoção de funções executivas em crianças, 2013. $288 \mathrm{f}$. Tese (Doutorado)- Universidade Presbiteriana Mackenzie. Pós- Graduação em Distúrbios do Desenvolvimento. Disponível em: $<$ http://tede.mackenzie.br/jspui/bitstream/tede/176 8/1/Natalia\%20Martins\%20Dias.pdf $>$. Acesso em: 14 mar. 2017.

DIAS, N. M.; MENEZES, A.; SEABRA, A. G. Alterações das funções executivas em crianças e adolescentes. Est. Inter. Psicol., Londrina , v. 1, n. 1, p. 80-95, 2010. Disponível em:

<http://pepsic.bvsalud.org/scielo.php?script=sci_ar ttext\&pid=S2236-

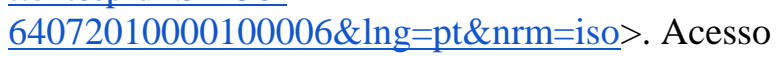
em 16 mar. 2017. 


\section{$16^{\circ}$ \\ ERGODESIGN USIHC CINAHPA}

$16^{\circ}$ Ergodesign - Congresso Internacional de Ergonomia e Usabilidade de Interfaces Humano Tecnológica: Produto, Informações Ambientes Construídos e Transporte

$16^{\circ}$ USIHC - Congresso Internacional de Ergonomia e Usabilidade de Interfaces Humano Computador

CINAHPA | 2017 - Congresso Internacional de Ambientes Hipermídia para Aprendizagem.
FONSECA, V. Papel das funções cognitivas, conativas e executivas na aprendizagem: uma abordagem neuropsicopedagógica. Rev.

psicopedag., São Paulo, v. 31, n. 96, p. 236-253, 2014. Disponível em:

$<$ http://pepsic.bvsalud.org/scielo.php?script=sci_ar ttext\&pid=S0103-

$84862014000300002 \& \operatorname{lng}=\mathrm{pt} \& \mathrm{nrm}=\mathrm{iso}>$. Acesso em: 16 mar. 2017.

KLOPFER, E.; OSTERWEIL, S.; SALEN, K. Moving learning games forward. The MIT Education. 2009. Disponível na URL;

http://education.mit.edu/papers/MovingLearningG amesForward_EdArcade.pdf . Acesso 16 de mar de 2014.

GEE, J. P. Lo que nos enseñan los videojuegos sobre el aprendizaje y el alfabetismo. Ediciones Aljibe: Málaga, 2004.

MURRAY, J. H. Hamlet no Holodeck: o futuro da narrativa no ciberespaço. São Paulo: Itaú Cultural UNESP, 2003.

OLIVEIRA-SOUZA, R; MOLL, J.; IGNÁCIO, F. A.; TOVAR-MOLL, F.; Cognição e Funções Executivas. In: LENT, R. (Coord.) Neurociência da mente e do comportamento. Rio de Janeiro: Guanabara Koogan, 2008. p. 287-302.

REEVE, J. Motivação e emoção. Rio de Janeiro, LTC, 2011.

ROJO, R.; ALMEIDA, E. M. Multiletramentos na Escola. In: ROJO, R., Pedagogia dos Multiletramentos: Diversidade cultural e de linguagens na escola, São Paulo: Parábola Editora, 2012, cap.1. Disponível em <catalogo.educacaonaculturadigital.mec.gov.br/.../r ojo_2012.doc>. Acesso em 28 dez. 2016.

SANTAELLA, L. Navegar no ciberespaço o perfil cognitivo do leitor imersivo. São Paulo: Paulus, 2004.

SENA, S.; SCHMIEGELOW, S. S.; PRADO, G. M. B. C.; Perassi, R. ; FIALHO, F. A. P.

Aprendizagem baseada em jogos digitais: a contribuição dos jogos epistêmicos na geração de novos conhecimentos.. RENOTE. Revista Novas Tecnologias na Educação, v. 4, p. 1-11, 2016. SILVA, O. (Multi)letramentos e formação de professores na sociedade digital: entretecendo (desa)fios, 2017. In: ALVES, L., MOREIRA, J. A. (orgs.) Tecnologias \& Aprendizagens Delineando Novos Espaços de Interação, Salvador: EDUFBA, 2017.

SOARES, M. Letramento e alfabetização: as muitas facetas, 2003. Disponível

em<http://www.scielo.br/pdf/rbedu/n25/n25a01.pd f $>$ Acesso: 20 nov. 2016.

Alfabetização e letramento: caminhos e descaminhos. Revista Pátio- Revista Pedagógica, São Paulo, p. 96-100, fev. 2004. Disponível em <http://www.acervodigital.unesp.br/bitstream/1234 56789/40142/1/01d16t07.pdf> Acesso: 20 nov.

2016.

OS LETRAMENTOS E A

CONSTRUÇÃO DA AUTONOMIA DO ALUNO

DE EaD, Revista Intersaberes, vol.10, n.20,

p.314-326 | mai.- ago. 2015 | 1809-7286.

Disponível em:

<http://www.uninter.com/intersaberes/index.php/re vista/article/view/378>. Acesso em: 15 mar. 2017.

FRAGOSO, S.; REBS, R. R.;REIS, B. M. S.;

SANTOS, L.; MESSA, D.; AMARO, M.;

CAETANO, M. Um panorama dos estudos de games na área da Comunicação nos últimos 15 anos. Anais do XXXVIII Congresso Brasileiro de Ciências da Comunicação. Rio de Janeiro, 2015.

Disponível em:

<http://portalintercom.org.br/anais/nacional2015/re sumos/R10-0207-1.pdf>. Acesso em 16 mar. 2017.

FRAGOSO, S.; REBS, R. R.;REIS, B. M. S.;

SANTOS, L.; MESSA, D.; AMARO, M.;

CAETANO, M.; KURTZ, G. B.; Tendências temáticas das trilhas do SBGames e das Teses e Dissertações sobre jogos defendidas no Brasil nos últimos 15 anos. Anais do XV Simpósio Brasileiro de Jogos e Entretenimento Digital. São Paulo, 2016. Disponível em:

<http://www.sbgames.org/sbgames2016/download s/anais/157675.pdf>. Acesso em 16 mar. 2017.

\section{Agradecimentos}

Gostaríamos de agradecer a todos que apoiaram e colaboraram com o nosso trabalho, como o colégio onde realizamos a pesquisa, o Centro de pesquisa Comunidades Virtuais e à nossa orientadora por toda a atenção que foi disponibilizada. 